\title{
Perfil dos gestores de Unidades Básicas de Saúde em São Luis-MA
}

\author{
Profile of managers of basic health units area in São Luis - MA
}

\author{
Emanuelly Souza Coelho ${ }^{1}$, Denise Carneiro Machado Cortez ${ }^{2}$, Cianna Nunes Rodrigues², \\ Francisca Maria Ferreira Noronha ${ }^{2}$, Lilia de Cássia Piedade Santiago ${ }^{2}$
}

Resumo: A gestão em saúde é um dos temas que tem convergido a partir das mudanças preconizadas pelo movimento da Reforma Sanitária e que desembocaram na construção do Sistema Único de Saúde, enfocando principalmente na qualidade da gestão dos serviços. Objetivou-se conhecer o perfil dos gestores de Unidades Básicas de saúde em São Luis-MA. Trata-se de um estudo descritivo, com abordagem quantitativa, realizado no período de abril e maio de 2012 nas Unidades Básicas de Saúde, contou com uma amostra de 32 gestores das US. A coleta de dados foi através de um questionário elaborado pela autora, aplicado durante o turno matutino em visita na Unidade. A análise dos dados foi feita com o auxilio do programa Excel 2007, e os resultados expostos em tabelas e gráficos para melhor compreensão. Respeitando-se os aspectos éticos e os critérios da Resolução CNS 196/96. Identificou-se neste estudo que 59\% dos gestores são do sexo feminino, quanto à faixa etária $44 \%$ tem entre 31 e 40 anos, $44 \%$ são casados/união estável. Quanto à formação, 69\% dos gestores são enfermeiros, 34\% estava formado entre 6 e 10 anos, $72 \%$ dos gestores não participaram de treinamentos para assumir a gerência, 34\% já haviam participado de cursos que contribuíram para o desenvolvimento de suas atividades gerenciais. Desses, $64 \%$ informou cursos de Gestão, 38\% dos gestores estão na direção da US entre 4 e 6 anos, $81 \%$ dos gestores das US informaram cargo por indicação política e $66 \%$ dos gestores estudados nunca tinham tido experiências anteriores com administração/gerência. A complexidade do setor exige conhecimento de gestão específica, objetivando uma tendência a tornar o setor mais profissional ensejando uma melhora na prestação de serviços.

Palavras-chaves: Perfil. Gestor. Unidade de Saúde.

\begin{abstract}
The health management is one of the themes that have converged from the changes recommended by the Sanitary Reform movement that led to the construction of the Health System focusing primarily on quality of service management. The objective was to know the profile of managers of Primary health care in Sao Luis, MA. This is a descriptive study with qualitative approach, carried out between April and May 2012 in the Basic Health, had a sample of 32 U.S. managers. Data collection was through a questionnaire prepared by the author applied during the morning shift on a visit at the Unit. Data analysis was performed with the help of Excel 2007, and the results presented in tables and graphs for better understanding. Subject to the ethical aspects and criteria of Resolution CNS 196/96. Identified in this study that $59 \%$ of managers are female, the age group $44 \%$ are between 31 and 40 years, $44 \%$ are married / stable union, As to training $69 \%$ of managers are nurses, $34 \%$ had graduated between 6 and 10 years, $72 \%$ of managers did not participate in training to take over the management, $34 \%$ had participated in courses that contributed to the development of their management activities, $64 \%$ reported these management courses, $38 \%$ of managers are will direction of the U.S. between 4 and 6 years, $81 \%$ of managers reported U.S. office by political appointment and $66 \%$ of managers studied had never had previous experience in administration / management. The complexity of the sector requires specific knowledge management, aiming a tendency to make the sector more professional occasioning an improvement in service delivery.
\end{abstract}

Keywords: Profile. Manager. Health Unit

1 - Graduado do Curso de Enfermagem - UNICEUMA

2 - Docentes - UNICEUMA

Rev. Invest, Bioméd., São Luís, 7:47-57. 2015 


\section{Introdução}

A composição de saúde no Brasil também sofreu alterações nos últimos 30 anos. Hoje utilizamos o modelo Sistema Único de Saúde (SUS), que tem como meta a cobertura universal de toda população brasileira e, neste contexto, a Estratégia da Saúde da Família (ESF) trabalha a família como núcleo social, objetivando prestar assistência integral às necessidades de saúde de uma população adstrita, intervindo sobre os fatores de risco aos quais a população está exposta, fazendo com que a saúde seja reconhecida como um direito de cidadania e, portanto, expressão de qualidade de vida ${ }^{1}$.

$$
\text { A ESF é apontada }
$$
como alternativa para reorganização da oferta de serviços de saúde e a proposta insere-se no âmbito do debate em torno das opções para reorientação do modelo assistencial vigente, predominantemente hospitalocêntrico e curativo. Assim, a estratégia em certos municípios brasileiros constitui-se em uma tática para solucionar problemas e necessidades inserindo-se entre os modelos alternativos ${ }^{2}$.

A expansão de Rede de Atenção à Saúde, impulsionada pelo processo de descentralização no Sistema Único de Saúde, além de operar mudanças na gestão e prestação de serviços no setor, também vem transformando 0 mercado de trabalho em saúde ${ }^{3}$.

A atenção primária à saúde oferecida pelas unidades de saúde (US) por muitas vezes se configura como a porta de entrada mais procurada pelo usuário ao sistema de saúde. Uma das sobrecargas, talvez a maior dos processos gerenciais da contemporaneidade, é conseguir coordenar adequadamente esta diversidade da demanda, aliada ainda à complexidade diversificada da necessidade de saúde. Por outro lado, concorre para as dificuldades da gerência a formação inespecífica dos trabalhadores ${ }^{4}$.

As Unidades Básicas de Saúde têm responsabilidades na implantação de novos programas, na identificação do perfil epidemiológico da população das áreas de abrangência, nas articulações do serviço com entidades comunitárias, com a rede hierarquizada de serviços de saúde e com os níveis centrais de decisão do município, com o objetivo de atender às necessidades de saúde da população. Para isto, torna-se imprescindível que o gestor mantenha o planejamento e a implementação de ações voltadas para 0 alcance de objetivos e metas estabelecidas e de um sistema de avaliação direcionado para a realidade local ${ }^{2}$.

Diante do desafio de oferecer qualidade nos atendimentos, o Ministério da Saúde desenvolve treinamentos no campo de desenvolvimento de recursos humanos em saúde, direcionado para a qualificação técnica e administrativa dos gestores das Unidades Básicas de Saúde (UBS), aumentando a capacidade gerencial, almejando mudanças nas práticas sanitárias e de atenção à saúde ${ }^{5}$.

$\mathrm{Na}$ prestação de serviços de saúde, a assistência basicamente é realizada por meio das pessoas: o processo inicia-se na portaria, prossegue com os profissionais de atendimento, passa ocasionalmente pelo profissional de limpeza, copeira, perpassa pelos médicos e outros profissionais de apoio que integram a equipe e contribuem para a realização do trabalho interdisciplinar. A conjunção de esforços para atingir bons resultados está relacionada diretamente com a atuação do gerente, que num contexto de 
ambiguidades e sobrecarregado de tarefas e variadas demandas, tem que buscar a efetiva realização do trabalho dentro das premissas estabelecidas pelo SUS e de acordo com os padrões de qualidade desejado pelos seus usuários ${ }^{6}$.

O tema "gestão" comporta processos complexos, relacionados com a demanda e necessidades de saúde. Não é suficiente que as decisões sejam pautadas em bom senso e experiências passadas. Bagagem de conhecimentos, capacidade de análise, capacidade de ação, aprimoramento de práticas e determinação em alcançar resultados se tornaram indispensáveis para 0 perfil gerencial que se busca nos tempos atuais ${ }^{7}$.

No gerenciamento, o gerente necessita dominar uma gama de conhecimentos e habilidades das áreas de saúde e de administração, bem como ter uma visão geral no contexto em que elas estão inseridas e compromisso social com a comunidade. Em suma, o gerente de uma UBS tem como atividade precípua a organização da produção de bens e serviços de saúde ao indivíduo ou à coletividade $^{8}$.

$\mathrm{Na}$ área de saúde, o gerenciamento de serviços detém características específicas e quem está à frente é o responsável pelo caminho a ser seguido pela instituição. Assim, espera-se do gestor uma sequência de ações inteligentes, planejadas, inovadoras e modernas, que levem à consecução da qualidade dos serviços na área de saúde. Os profissionais de linha de frente são os responsáveis pela entrega do serviço e devem fazer isso de maneira alinhada ao que foi estabelecido pela gerência ${ }^{9}$.

Em São Luís, de acordo com os dados divulgados pelo Cadastro Nacional dos Estabelecimentos de Saúde (CNES), existem 46 UBS's, distribuídas entre Unidades Básicas de Saúde e Centros de Saúde. Cada uma dessas unidades conta com equipes de profissionais específicos para atender os moradores de uma determinada área de abrangência. Em cada UBS há um gerente administrativo. A esse gerente cabe assumir suas atividades que comportam doses variadas de ambiguidade e incertezas.

Assim, justifica-se a relevância desse estudo objetivando conhecer o perfil dos gestores de Unidades Básicas de saúde em São Luís-MA, onde a gerência dos serviços de saúde deve ser tomada como um instrumento que pode possibilitar 0 compartilhamento de poder no interior das unidades e equipes de saúde e, neste sentido, poderá se constituir em uma ferramenta importante na efetivação de políticas públicas.

\section{Metodologia}

Trata-se de um estudo descritivo, de campo, prospectivo, com abordagem quantitativa, realizado no período de abril e maio de 2012. O estudo foi realizado nas Unidades Básicas e Centros de Saúde do município de São Luís-MA. A amostra foi composta por 32 gestores que administram as Unidades estudadas.

$O$ instrumento utilizado foi um questionário de questões fechadas, elaborado pela autora, que reuniu informações sobre dados socioculturais, a categoria profissional, a existência de capacitações dos gestores entre outras informações. Os dados foram coletados durante visita às Unidades de Saúde nos horários matutino e vespertino durante as terças e quintas-feiras. A análise dos dados foi feita com o auxílio do programa da Microsoft Excel e os resultados expostos em tabelas e gráficos para melhor compreensão. 
Por se tratar de pesquisa com seres humanos, respeitaram-se os aspectos éticos baseados na Resolução CNS no 196/96. O questionário foi aplicado a todos os gestores que se dispuserem a participar e assinar um Termo de Consentimento Livre e Esclarecido.

\section{Resultados e discussão}

A amostra do estudo foi composta de 32 gestores que administram as US estudadas. Os resultados foram expostos em forma de tabelas e gráficos, para uma melhor análise e discussão.

Tabela 1- Distribuição dos gestores estudados quanto ao sexo, faixa etária, situação conjugal e formação em US em São Luis -MA, 2012.

\begin{tabular}{lll}
\hline VARIAVÉIS & $\mathbf{N}$ & $\%$ \\
\hline Sexo & 13 & $41 \%$ \\
Masculino & 19 & $59 \%$ \\
Feminino & $\mathbf{3 2}$ & $\mathbf{1 0 0}$ \\
\hline TOTAL & 5 & \\
\hline Faixa Etária & 14 & $44 \%$ \\
25 a 30 anos & 10 & $31 \%$ \\
31 a 40 anos & 3 & $9 \%$ \\
41 a 50 anos & 32 & $\mathbf{1 0 0}$ \\
51 a 60 anos & & \\
\hline TOTAL & 14 & $44 \%$ \\
\hline Situação Conjugal & 8 & $25 \%$ \\
Casado (a)/ União estável & 2 & $6 \%$ \\
Solteiro (a) & 8 & $25 \%$ \\
Viúvo (a) & $\mathbf{3 2}$ & $\mathbf{1 0 0}$ \\
Divorciado (a) & & \\
\hline TOTAL & 2 & $6 \%$ \\
\hline Formação & 9 & $28 \%$ \\
Técnico & 21 & $66 \%$ \\
Superior & $\mathbf{3 2}$ & $\mathbf{1 0 0}$ \\
Pós-graduação & & \\
\hline TOTAL & & \\
\hline
\end{tabular}

De acordo com a Tabela 1, a distribuição dos gestores das US segundo o sexo, $59 \%$ (19) era do sexo feminino, quanto a faixa etária $44 \%$ (14) tinham entre 31 e 40 anos, 31\% (10) entre 41 e 50 anos, 16\% (5) tinham entre 25 e 30 anos, 9\% (3) entre 51 e 60 anos.

Em estudo semelhante, Magalhães e Duarte $^{10}$ encontraram quanto à faixa etária dos gerentes, que $83,03 \%$ dos mesmos encontravam-se na faixa de idade entre 36 e 50 anos. Percebe-se, assim, que se por um lado o quadro gerencial possui maior maturidade profissional, por outro lado, os profissionais mais jovens, ou em início de carreira, têm tido menos oportunidades de assumir cargo gerencial nas UBS do município.

Ainda na Tabela 1 observa-se que $44 \%$ (14) dos gestores são casados/união estável, $25 \%$ (8) são 
solteiros (as) e divorciados e 6\% (2) viúvos (as).

De acordo com Fontinele Junior $^{11}$, o fato de os gestores serem casados ou solteiros causa alguma influência no grau de comprometimento. Januário ${ }^{12}$ afirma que os casados são os mais propensos a desenvolver 0 comprometimento afetivo, enquanto aqueles que reforçam a relação custobenefício, favorável à permanência no emprego, são as mais propensas a desenvolver 0 comprometimento instrumental. De forma coerente, portanto, o comprometimento organizacional/afetivo apresentou forte correlação com a percepção das políticas de gestão.

Observa-se ainda que 66\% (21) dos gestores são pós-graduados, 0 que, segundo $\mathrm{Mezomo}^{13}$, pode ser justificado como uma real necessidade do mercado de trabalho que apresenta-se cada vez mais exigente onde a cada dia se trabalha mais a questão "qualidade."

Corrobora com essa idéia Laverde $^{14}$, afirmando que a demanda por profissionais qualificados e com formação superior é a grande exigência do mercado da área de Gestão Hospitalar. Uma unidade de saúde exige uma administração profissional capaz de the garantir organização, recursos humanos competentes, equipamentos e materiais que possibilitem qualidade na prestação dos serviços e custos adequados, especialmente na área pública e na rede conveniada ao Sistema Único de Saúde (SUS). profissional

Gráfico 1- Distribuição dos gestores estudados quanto à categoria

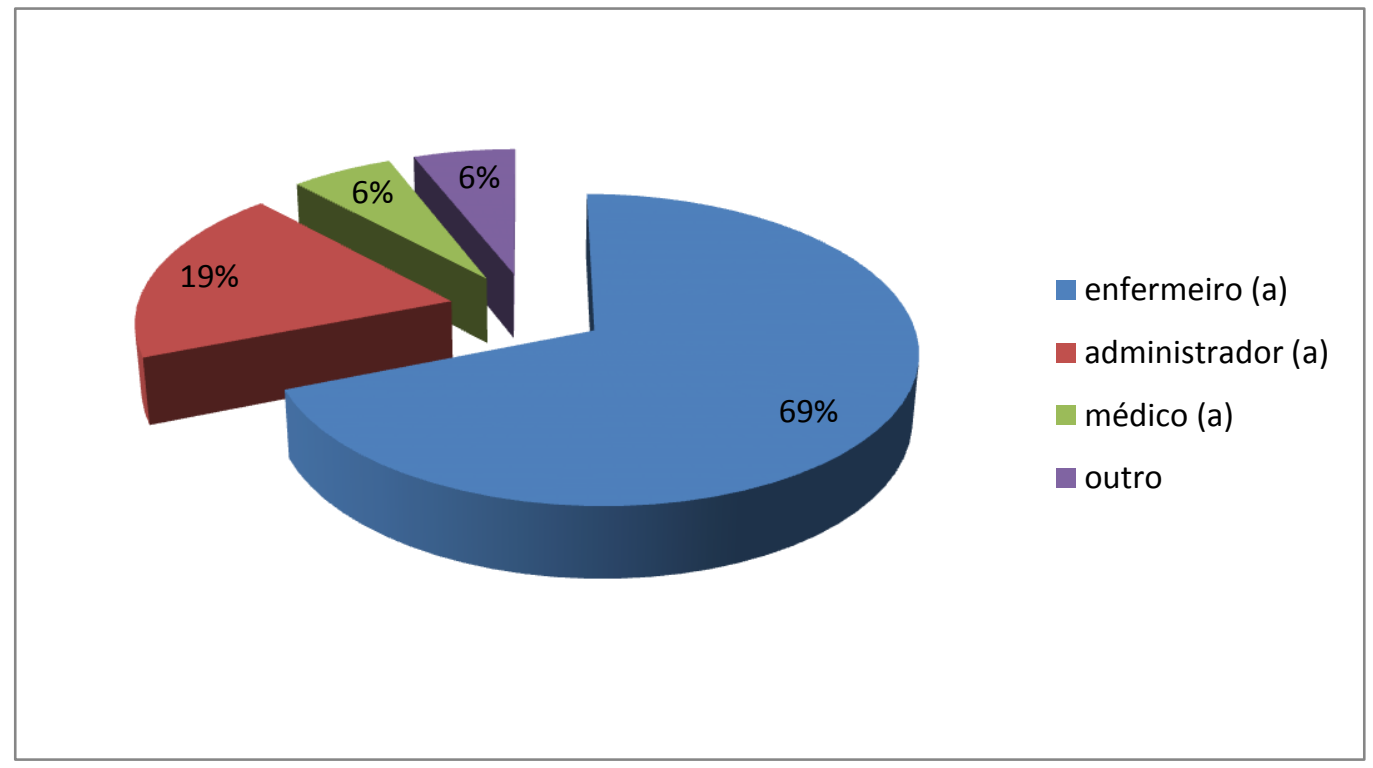

Conforme o Gráfico 1, 69\% (22) dos gestores são enfermeiros, $19 \%$ (6) administradores, e $6 \%$ de médicos e outras categorias profissionais.

Em estudo semelhante ${ }^{15}$ em Belo Horizonte: $49,15 \%$ dos gestores das US eram Enfermeiros; 13,57\% Odontólogos; 13,57\% Psicólogos;
8,49\% Médicos; 5,08\% Assistente Social; e 10,14\% dividem-se entre Terapeutas Ocupacionais $(1,69 \%)$ e outras profissões.

Confirmando o achado desse estudo, Malik e Teles ${ }^{16}$ referem que no Brasil, a maioria dos dirigentes nos hospitais são médicos e enfermeiros 
que aprenderam a coordenar o hospital no dia-a-dia. Os autores afirmam que ainda existe uma carência de cursos de administração para a área de saúde.

Catani $^{17}$ constata que a formação profissional é uma expressão recente que designa processos históricos referentes à capacitação para e o trabalho, assumindo uma relação permanente entre o trabalhador e o processo de trabalho. Na sua acepção mais ampla, designa todos os processos educativos que permitam ao indivíduo adquirir e desenvolver conhecimentos teóricos, técnicos e operacionais relacionados à produção de bens serviços desenvolvidos nas escolas ou nas empresas.

Gráfico 2- Distribuição dos gestores estudados quanto ao tempo de formação

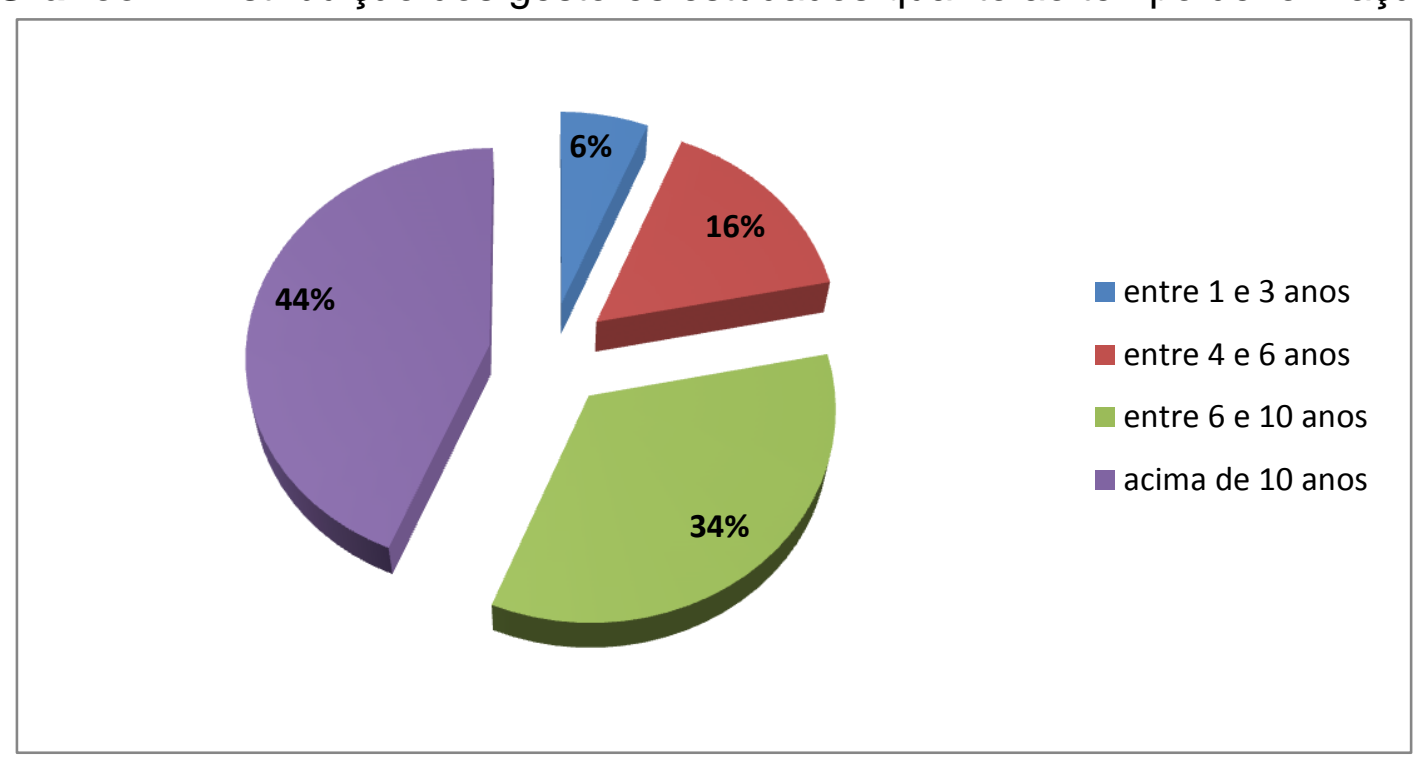

Conforme 0 Gráfico 2 observamos que $44 \%$ (14) dos gestores tinham acima de 10 anos de formação, 34\% (11) tinham entre $6 \mathrm{e}$ 10 anos de formação, $16 \%$ (5) entre 4 e 6 anos, e $6 \%$ ( 2) entre 1 e 3 anos.

Pelos resultados apresentados em estudo de Nóbrega et al. ${ }^{18}$, estimase que o fato de possuir maior tempo de formado dá ao profissional mais maturidade e experiência para exercer cargos de gerência Por outro lado, sabe-se que a formação dada pela universidade, há 10 anos, ainda estava atrelada às teorias administrativas funcionais na ótica taylorista-fordista.

Alves, Penna e Brito $^{15}$ corroboram tais afirmações quando criticam que os conteúdos repassados na formação acadêmica subestimam a complexidade do contexto organizacional, limitando-se a apresentá-los sob a fundamentação mecanicista.

Observando a Tabela 2 percebe-se que $72 \%$ (23) dos gestores não participaram de treinamentos para assumir a gerência, 34\% (11) já haviam participado de cursos que contribuíram para o desenvolvimento de suas atividades gerenciais.

Silva ${ }^{19}$, em sua tese de doutorado, defende sobre a importância da capacitação e das características pessoais dos gestores que lideram os processos de mudança e cita seis características que considera importantes nestes profissionais: o senso de justiça, a capacidade de decidir, o comportamento ético, a capacidade de 
condução política, a capacidade de transmitir confiança e a responsabilidade.

Tabela 2- Distribuição dos gestores quanto a treinamentos, participação em cursos e os cursos realizados em US em São Luis -MA, 2012.

\begin{tabular}{lll}
\hline VARIAVÉIS & $\mathbf{N}$ & $\%$ \\
\hline Treinamento para assumir a gerência & & \\
Sim & 9 & $8 \%$ \\
Não & 23 & $72 \%$ \\
\hline TOTAL & $\mathbf{3 2}$ & $\mathbf{1 0 0}$ \\
\hline Participação em cursos que contribuíram para & & \\
a atividade gerencial & & \\
Sim & 11 & $34 \%$ \\
Não & 21 & $66 \%$ \\
\hline TOTAL & $\mathbf{3 2}$ & $\mathbf{1 0 0}$ \\
\hline Cursos realizados & $\mathbf{N}$ & $\%$ \\
Planejamento & 2 & $18 \%$ \\
Recursos Humanos & 1 & $9 \%$ \\
Liderança & 1 & $9 \%$ \\
Gestão & 7 & $64 \%$ \\
\hline TOTAL & $\mathbf{1 1}$ & $\mathbf{1 0 0}$ \\
\hline
\end{tabular}

Os cursos existentes de capacitação de gestores deveriam contemplar os seguintes temas: Estado, Sociedade e Políticas Públicas, Administração, Planejamento e Estratégia, Economia da Saúde, Liderança e Mudanças e Teoria das Organizações, sugere Silva ${ }^{20}$.

Segundo Alves, Penna e Brito ${ }^{15}$, a complexidade dos serviços de saúde, os critérios nem sempre adequados de escolha dos gerentes como atores estratégicos para a organização dos serviços, a fragilidade e descontinuidade dos programas de educação permanente, 0 conhecimento sobre quem são os trabalhadores que atuam na área gerencial pode oferecer subsídios para a implementação de projetos de capacitação voltados para a realidade local e, conseqüentemente, para a efetivação das políticas públicas de saúde.

A Tabela 2 informa ainda que dos $34 \%$ (11) dos gestores que participaram de cursos, 64\% (7) informaram cursos de Gestão, 18\% (2) cursos de Planejamento e em igual valor $9 \%$ (1) realizaram treinamentos de Liderança e Recursos Humanos.

Segundo Brasil ${ }^{21}$, há uma política de educação para o SUS sendo implementada. Existem polos de educação permanente, reunindo gestores estaduais e municipais do SUS, hospitais universitários, instituições de educação superior, escolas técnicas, além de representantes do controle social e estudantes. 
Gráfico 3- Distribuição dos gestores estudados quanto ao tempo de gestão na US.

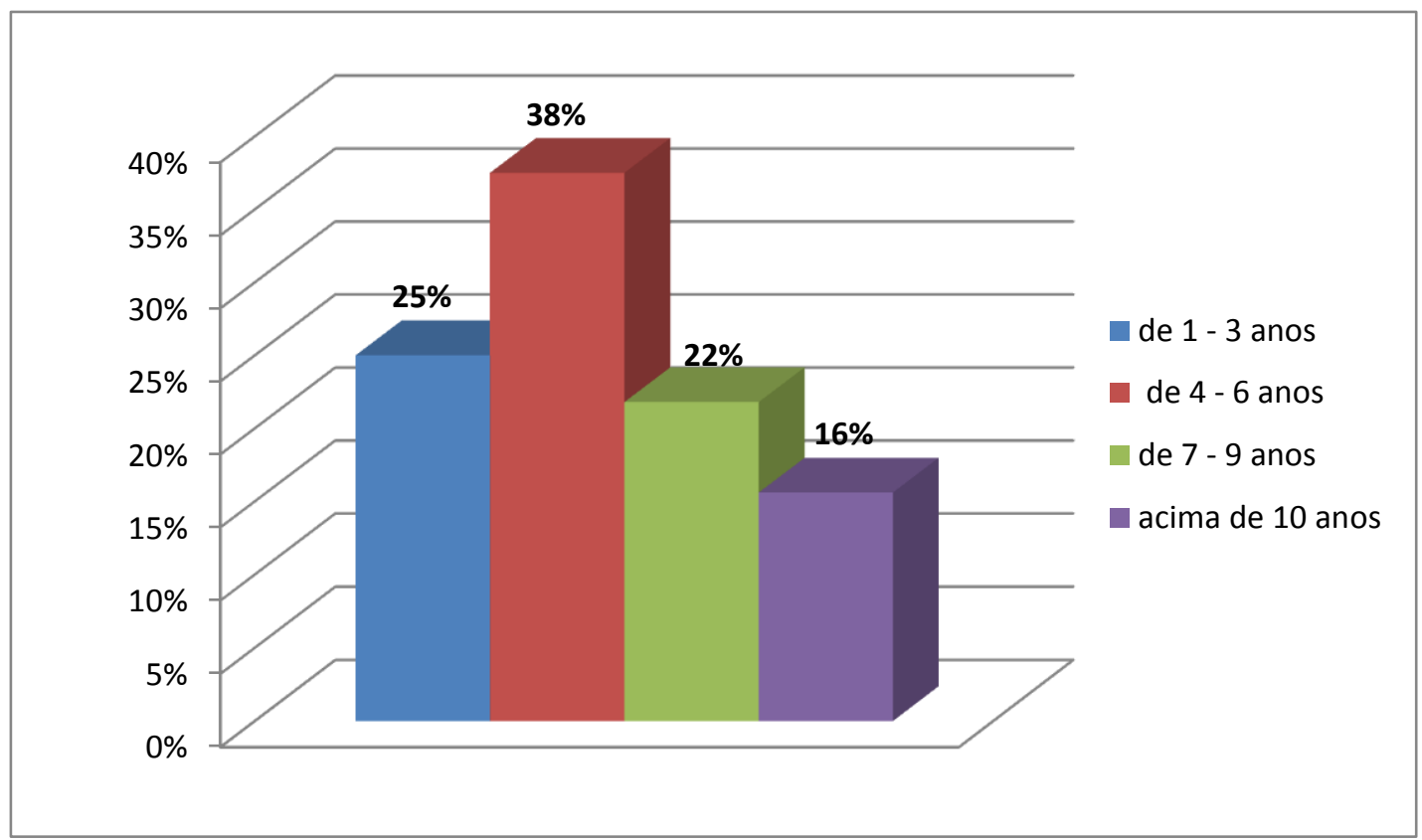

Analisando o Gráfico 3 observase que $38 \%$ (12) dos gestores estão na direção das US entre 4 e 6 anos, $25 \%$ (8) entre 1 e 3 anos, $22 \%$ (7) entre 7 e 9 anos e $16 \%$ (5) acima de 10 anos.

Em estudo, Andre e Ciampone $^{22}$, ao abordarem o tempo de exercício da função, $90 \%$ dos gerentes ocupavam essa posição entre três e cinco anos, $10 \%$ haviam assumido há menos de um ano e somente $20 \%$ deles possuíam experiência em gestão em outros serviços, distintos da Secretaria Municipal de Saúde.

Alves, Penna e Brito ${ }^{15}$ reforçam que, apesar de se caracterizar como um cargo de confiança, não é observada mudança significativa nos períodos eleitorais. O que nos leva a pensar em uma redução de indicações políticas para a ocupação do cargo, quando constata-se 0 tempo de permanência no cargo.

Gráfico 4 - Distribuição dos gestores estudados quanto à forma de ascensão ao cargo de gestor

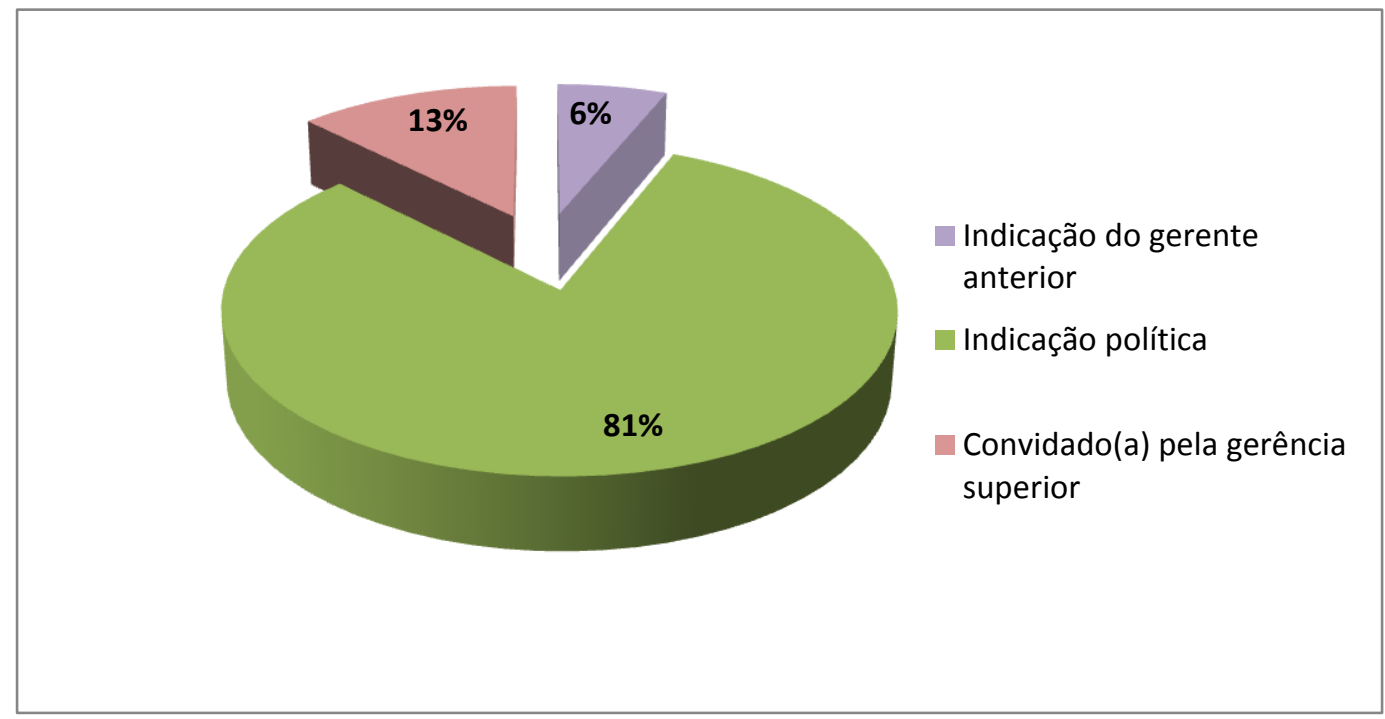


Conforme o Gráfico 4 observase que $81 \%$ (26) dos gestores das US informaram ter sido indicado por político para a administração da Unidade, $13 \%$ (4) foram convidados por gerência superior e $6 \%$ (2) convidados pelo gestor anterior.

André e Ciampone ${ }^{22}$ defendem que para haver a ascensão de profissionais à posição de gestor de uma Unidade Básica de Saúde ou a quaisquer serviços de saúde, deveria ser instituído um sistema de avaliação de competências e certificação de formação profissional meritória, na qual cursos específicos de Gestão em Saúde fossem pré-requisitos. Isto porque se sabe que o despreparo do gestor influencia diretamente o modo de operacionalização das estratégias e a dinâmica das equipes envolvidas nos serviços podendo levar à ineficácia e ineficiência dos processos.

Gráfico 5 - Distribuição dos gestores estudados quanto a experiências anteriores em gestão

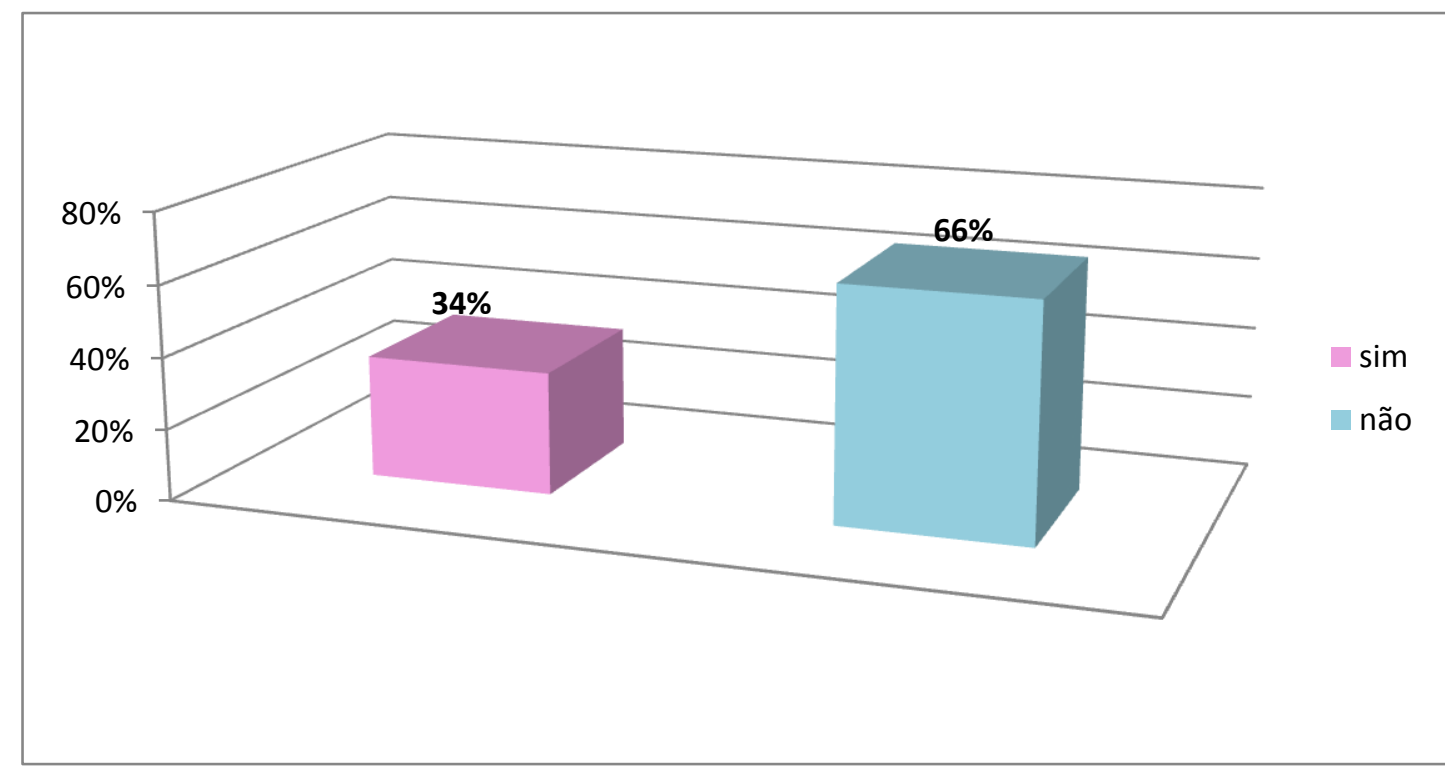

O Gráfico 5 mostra que 66\% (21) dos gestores estudados nunca tinham tido experiências anteriores com administração/gerência, e 34\% (11) já haviam desenvolvido atividades de gestão.

A experiência prática dos gerentes como conhecimento prévio, não significa claramente conhecimento em gestão pública. Esse dado é relevante e pode explicar parte das dificuldades enfrentadas pelos gerentes no exercício da função, pois afirma Laranjeira ${ }^{22}$, a existência de deficiências da gerência pública e a inadequação dos profissionais para o atendimento das atuais demandas organizacionais.

Laverde $^{14}$ argumenta que a partir da constatação de forte relação entre as experiências anteriores de trabalho, que recrutar e selecionar empregados nem sempre estão interligados. Para esses autores, o colaborador no qual se deposita confiança torna-se comprometido, interioriza o valor do trabalho e seus objetivos, estando mais propenso a 
identificar-se com o cargo e desempenhá-lo com compromisso.

\section{Conclusão}

Identificou-se neste estudo que $59 \%$ (19) dos gestores são do sexo feminino. Quanto à faixa etária $44 \%$ (14) tem entre 31 e 40 anos, 44\% (14) são casados/união estável. Quanto à formação 69\% (22) dos gestores são enfermeiros, $66 \%$ (21) dos gestores são pós-graduados, 34\% (11) estava formado entre 6 e 10 anos, $72 \%$ (23) dos gestores não participaram de treinamentos para assumir a gerência, $34 \%$ (11) já haviam participado de cursos que contribuíram para 0 desenvolvimento de suas atividades gerenciais, desses 64\% (7) informaram cursos de Gestão, 38\% (12) dos gestores estão em direção de US entre 4 e 6 anos, $81 \%$ (26) dos gestores das US informaram cargo por indicação política e $66 \%$ (21) dos gestores estudados nunca tinham tido experiências anteriores com administração/gerência.

Portanto, o perfil desejado do gestor em saúde, capaz de atender às necessidades da comunidade, corresponde ao profissional voltado para as áreas de gestão hospitalar e de outros serviços de saúde, habilitado para o gerenciamento de unidades de produção e de apoio administrativo, em instituições de saúde mantidas pelo poder público e pela iniciativa privada. A competência esperada visa à compreensão da necessidade do contínuo aperfeiçoamento profissional e do desenvolvimento da autoconfiança, que levarão o profissional a obter níveis crescentes de complexidade administrativa.

\section{Referências}

1. Coelho, R. Perspectivas de Inserção do Profissional de Serviço Social nas Equipes Básicas do Programa Saúde da Família. 2006. Tese (Graduação em Serviço Social), UFRJ, Rio de janeiro.

2. Costa, N.R; Pinto, L.F. Piso da Atenção Básica: mudanças na estrutura. In: Negri, B; Viana, A.L.D organizadores. O Sistema Único de Saúde em dez anos de desafio. São Paulo: Sobravime; 2002. p. 271-98

3. Ferreira, J. S. Gerenciamento na Atenção Primária à Saúde: potencialidades e desafios vivenciados pelos gestores. Disponível em www.sbpcnet.org.br/livro/63ra/conpe ex/pivic/.../JOYCE SA.PDF. Acesso em 02 de março de 2012.

4. Merhy, E. E. Um dos grandes desafios para os gestores do SUS: apostar em novos modelos dede atenção. IN: Merhy, E. E. et al. O trabalho em saúde: olhando e experienciando o SUS no cotidiano. São Paulo: HUCITEC, 2003.

5. Starfield, B. Atenção Primária: equilíbrio entre necessidades de saúde, serviços e tecnologia. Brasília: Unesco Brasil, Ministério da Saúde; 2004.

6. Davel, E.; Melo, M. C. de O. L. Gerência em ação: singularidades e dilemas do trabalho gerencial. Rio de Janeiro: Editora FGV, 2005.

7. Ruano, A. Gestão por competências. Editora Qualitymark, 2003

8. Passos, JP; Ciosak, SI. A concepção dos enfermeiros no processo gerencial em uma Unidade Básica de Saúde. Rev Esc Enferm USP 2006; 40(4):464-8. 
www.ee.usp.br/reeusp/acesso em 01.03.2012.

9. Taraboulsi, F. A. Administração de hotelaria hospitalar. 16 ed. São Paulo: Atlas, 2006.

10. Magalhães, A.M.M; Duarte, E.R.M. Tendências gerenciais que podem levar a enfermagem a percorrer novos caminhos. Rev Bras Enferm. 2004; 57: 408-11.

11. Fontinele Júnior, K. Administração hospitalar. Goiânia: AB, 2002.

12. Januário, J.J.H. Factores que podem influenciar os Indicadores de performance (Indicadores de Gestão Hospitalar). Tese de Mestrado, Lisboa, 2009.

13. Mezomo, J. C. Gestão da qualidade na saúde. Princípios básicos. São Paulo: 2001

14. Laverde, P. Administração hospitalar. 2. ed. Rio de Janeiro: Guanabara Koogan, 2002.

15. Alves, M.; Penna, C.M. de M.; Brito M.J.M.; Perfil dos gerentes de Unidades Básicas de Saúde. Rev Bras Enferm, Brasília (DF) 2004 julago;57(4):441-6.

16. Malik, A. M.; Teles J. P. Hospitais e programas de qualidade no Estado de São Paulo. Revista de Administração de Empresas, São Paulo, v.41, n.3, p.51-9, jul.set.2001.

17. Cattani, A.D. Trabalho e tecnologia. Dicionário crítico. $3^{\underline{a}}$ ed. Petrópolis(RJ): Vozes;2000.

19. Nóbrega, M.de F.B.; Matos, M.G.; Silva, L.M.S.da; Jorge, M.S.B. Perfil gerencial de enfermeiros que atuam em um hospital público federal de ensino. Rev. enferm. UERJ, Rio de Janeiro, 2008 jul/set; 16(3): 333-8.

20. Silva, S.F. Municipalização da saúde e poder local: sujeitos, atores e políticos [tese]. São Paulo: Faculdade de Saúde Pública, Universidade de São Paulo; 2001.

21. Brasil, Ministério d Saúde. Relatório das Conferências Nacionais de Saúde. Ministério da Saúde. Brasília - DF: 2005.

22. André, A.M.; Ciampone, M.H.T. Competências para a gestão de Unidades Básicas de Saúde: percepção do gestor. Rev Esc Enferm USP, 2007; 41(Esp):835-40. www.ee.usp.br/reeusp.

23. Laranjeira, S. M. G. Qualificação (verbete). In A. D. Cattani (Org.), Trabalho e tecnologia: dicionário crítico. Petrópolis: Vozes. 2000. 